\title{
Evaluation of performance and personal satisfaction of the patient with spastic hand after using a volar dorsal orthosis
}

\author{
Danielle dos Santos Cutrim Garros ${ }^{1}$ Rubens José Gagliardi², \\ Regina Aparecida Rossetto Guzzo ${ }^{3}$
}

\begin{abstract}
The performance and the satisfaction of the patient were quantitatively compared with the use of the volar dorsal orthosis in order to position the spastic hand. Thirty patients wearing the orthosis for eight hours daily were evaluated by the Canadian Occupational Performance Measure and the box and blocks test, for a three-month period. Five activities were selected (among daily life activities, productive activities, and leisure activities) by the patients, which were impaired by spasticity. There was an improvement related to performance after use of orthosis, with an average of $1.4 \pm 0.5$ to $6.3 \pm 0.8(p<0.01)$. Patient satisfaction average after wearing the orthosis was of $1.7 \pm 0.4$ to $6.3 \pm 0.6(p<0.01)$. In this casuistic, the use of orthosis for wrist and finger spasticity has shown an improvement in the functional performance and patient satisfaction.
\end{abstract}

Key words: occupational therapy, hand, splint, performance, hemiplegia, stroke, rehabilitation.

Avaliação do desempenho e da satisfação pessoal do paciente com mão espástica após o uso da órtese dorsal volar

\section{RESUMO}

Comparou-se quantitativamente o desempenho e a satisfação do paciente com o uso da órtese dorsal volar para posicionamento da mão espástica. Foram analisados 30 pacientes que fizeram uso da órtese por 8 horas diárias, avaliados por meio da Medida Canadense de Desempenho Ocupacional e teste caixa e blocos, no intervalo de 3 meses. Foram selecionadas 5 atividades (entre as atividades de vida diária, produtivas e de lazer) pelos pacientes que estavam comprometidas pela espasticidade. Obteve-se melhora em relação ao desempenho após o uso da órtese, com média de $1,4 \pm 0,5$ para $6,3 \pm 0,8(p<0,01)$. Quanto à média da satisfação foi de $1,7 \pm 0,4$ para $6,3 \pm 0,6(p<0,01)$ com o uso da órtese. Nesta casuística, o uso da órtese de punho e dedos para espasticidade apresentou melhora no desempenho funcional e satisfação do paciente.

Palavras-chave: terapia ocupacional, mão, contenções, avaliação de desempenho, monoplegia, acidente cerebral vascular, reabilitação.

\section{Correspondence}

Danielle dos Santos Cutrim Garros

Rua Canuto do Val 67 / 51

01224-040 São Paulo SP - Brasil

E-mail: danica.net@terra.com.br

\section{Support}

This study was support by CAPES

Received 26 March 2009

Received in final form 6 October 2009

Accepted 19 October 2009
Spasticity is the most incapacitating complication after a stroke $\mathrm{e}^{1,2}$ due to the motor restriction it causes. In this study, the use of orthosis, an external device applied to the hand, is indicated in order to prevent deformities besides,improving positioning and increasing comfort ${ }^{3-8}$. The goal is to quantitatively compare the perfomance and the personal satisfaction of the patient with spastic hand due to a stroke, after wearing volar dorsal orthosis for positioning.

\section{METHOD}

A prospective study with 30 patients 
with spasticity in one of the hands caused by a stroke was performed from May to November, 2007, in the Occupational Therapy Department of the Rehabilitation Service of Irmandade da Santa Casa de Misericórdia de São Paulo. All the patients who fulfilled the criteria described above and did not show cognitive deficit, mobility impairments without aid, neuropathic pain, or any other neurologic complications and had purchased orthoses for wrist and fingers positioning were subsequently admitted. The patients were analyzed both in the baseline and in the third month for the variables aforementioned. All patients received Occupational Therapy treatment aiming at functional training, daily life activities training and upper members stretching.

Nineteen patients belonged to the male gender (63\%). As for the post- stroke period, 6 (20\%) patients were 7 or more years, 3 (10\%) ranging from 5 to 6 years, 5 (17\%) 3 to 4 years, and 16 (53\%) between 1 and 2 years. With regard to anthropometry, 28 (93\%) were right-handed, and 2 (7\%) left-handed. As for the side affected, 12 (40\%) were on the right side, and 18 (60\%) on the left side.

The orthoses for wrist and fingers positioning were manufactured of thermoplastic material such as Ezeform, with $3.2 \mathrm{~mm}$ thick for all patients. All patients were instructed to wear the orthoses with brackets in the dorsal and ventral areas for eight hours during the day as well as at night, daily. The evaluations were perfomed with a 3-month interval through the Canadian Occupational Performance Measure and the Box and Block Manual Dexterity Test, in order to collect functional references for the hand.

The block box test was performed using a wooden Box $53.7 \mathrm{~cm}$ long and $24.5 \mathrm{~cm}$ wide, with a partition in the centre resulting in two equal sides, containing 150 cilindrical wooden. The patient was required to grasp one block at a time, transport it over the partition and release it into the opposite side, and was given one minute for the task. The amount of blocks moved corresponds to the functional ability of the hand ${ }^{9-11}$. In the current work, the positioning of the patient was adapted due to the synergy in the upper member, which would impair the holding function of the spastic side, with the patient standing before the box in the horizontal position, at a height and distance that allowed the patient to see and handle the pieces. The test was performed with both hands.

The Canadian Occupational Performance Measure was applied by the identification of the tasks impaired by spasticity, in the areas of daily life activities (grooming, mobility, outdoor independence), productive activities (job, house chores, education), and leisure activities. Scores were given from 1 to 10 , according to the degree of importance of the taks to be performed by the patient. Then, five tasks were chosen among the ones identified in the first step, in order of importance to the patients. Scores from 1 to 10 were given to performance and satisfaction. Both evaluations were performed before (baseline) and 3 months after the use of orthosis.

The results for the different segments studied were compared at times 0 and 3 months, through EPI info statistical software, and SSP by the Wilcoxon test. The level of significance adopted was of $5 \%$.

The study was approved by the Ethics and Research Committee in Human Beings of Irmandade da Santa Casa de Misericórdia de São Paulo, process number 305/07. Consent forms were signed by all patients.

\section{RESULTS}

The results are presented in Tables 1, 2 and 3 .

As regard to the activities which were impaired informed by the patients, based on the 5-level model, the daily life activities range between $60 \%$ and $90 \%$ and it is present in all levels, followed by the productive activities ranging from $5 \%$ to $20 \%$ also present in all levels, followed by leisure activities, present in the $2^{\text {nd }}$ and $4^{\text {th }}$ levels, ranging from $5 \%$ to $18 \%$ (Fig 1).

Among the daily life activities, dressing, hygiene, feeding, outdoor mobility and independence were mentioned. Activities related to dressing were selected in all levels, from $15 \%$ to $42 \%$; hygiene-related tasks were also selected in all levels, ranging from $15 \%$ to $32 \%$; feeding in the $1^{\text {st }}, 3^{\text {rd }}$ and $5^{\text {th }}$ levels, from $2 \%$ to $23 \%$; mobility between $18 \%$ and $42 \%$ in all levels; and outdoor activities related to independence from $2 \%$ to $23 \%$, mentioned in all levels (Fig 2).

As regard to performance in the motor coordination Block Box Test, the average was 48 blocks per minute prior to treatment for the non-impaired side, with a deviation pattern of 14. After the treatment, the average increased to 59 blocks per minute, with a deviation pattern of 15 . The impaired side showed an average of 1 block per minute pre-treatment, with a deviation pattern of 3 , and following the treatment, the average rose to 6 blocks per minute, with a deviation pattern of 12 (Table 1 ).

The average performance score for the Canadian Occupational Performance Measure was 1.4 pre-treatment, with a 0.5 deviation pattern, and it increased to 6.3 , with a deviation pattern of 0.8 (Table 2).

As for satisfaction, the pre-treatment average was 1.7 with 0.4 of deviation pattern and the post-treatment average was 6.3 with a deviation pattern of 0.6 (Table 3 ).

\section{DISCUSSION}

In the area of the performance of the daily life activities (DLA), self-care activities, such as hygiene, feeding and dressing, are selected with the greater indexes in all levels of patient needs (Graph 1), corroborating the studies by Hinderer and Dixon ${ }^{12}$, Pfister et al. ${ }^{13}$, Satku- 
Table 1. Result of the box and block test in both sides (impaired and normal) (blocks per minute).

\begin{tabular}{lccccc}
\hline & \multicolumn{2}{c}{ Normal side } & & \multicolumn{2}{c}{ Impaired side } \\
\cline { 2 - 3 } \cline { 5 - 6 } & $\begin{array}{c}\text { Average } \pm \\
\text { Std deviation }\end{array}$ & $\mathrm{p}$ & & $\begin{array}{c}\text { Average } \pm \\
\text { Std deviation }\end{array}$ & $\mathrm{p}$ \\
\hline Before the treatment & $48 \pm 14$ & $<0.01$ & & $1 \pm 3$ & $<0.01$ \\
After the treatment & $59 \pm 15$ & $<0.01$ & & $6 \pm 12$ & $<0.01$ \\
\hline
\end{tabular}

Presentation of the result through the average, standard deviation, and probability values.

Table 2. Result of general performance.

\begin{tabular}{lcc} 
& Average \pm Std deviation & $\mathrm{p}$ \\
\hline Before the treatment & $1.4 \pm 0.5$ & $<0.01$ \\
After the treatment & $6.3 \pm 0.8$ & $<0.01$ \\
\hline
\end{tabular}

Presentation of the result through the average, standard deviation, and probability values.

Table 3. Result of general satisfaction.

\begin{tabular}{lcc}
\hline & Average \pm Std deviation & $\mathrm{p}$ \\
\hline Before the treatment & $1.7 \pm 0.4$ & $<0.01$ \\
After the treatment & $6.3 \pm 0.6$ & $<0.01$ \\
\hline
\end{tabular}

Presentation of the result through the average, standard deviation, and probability values.

nam ${ }^{14}$, Cup et $\mathrm{all}^{15}$, who highlighted the priorities related to the loss of autonomy over the self-care activities. In addition to corroborating the works previously mentioned, dressing, mobility (getting up, sitting down, and walking, where the upper member is supposed to support and provide balance throughout walking), and hygienerelated tasks were considered predominant in all levels of needs. Performing these activities ensures that the physiological needs of human beings be fulfiled and plays an important social role as self care represents physical, pychological, and financial well-being. The individual who is able to take care of him/herself is ready to be successful at performing other tasks, such as in the productive and leisure areas, as well as taking up other occupational roles referred by Nelson and Jepson-Thomas ${ }^{16}$, such as becoming a parent, a professional, among others.

The patient tends to choose survival-related tasks when questioned about his/her first need, aiming to become less dependent on other people. In that context, the hand is essential due to its holding function that enables handling of objects according to the individual's interests. In order to perform daily tasks, the movements required are thick gripping, steady pliers, and motor skills, such as in buttoning up or fastening clothes.

Still concerning DLA, considering outdoor independence, tasks such as going shopping, holding bags, driving, and counting bills were mentioned. That kind of task was constant in all levels, though less frequent. In that case, besides motor skills, emotional safety is necessary,

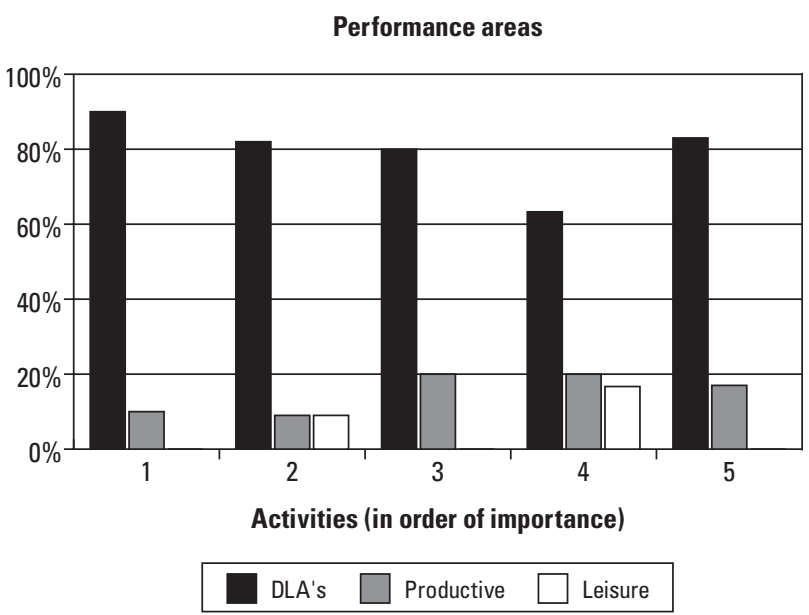

Fig 1. Percent/Activities Ratio (daily life activities - DLA's, productive, and leisure activities) impaired by the spastic hand in order of importance for the patient.

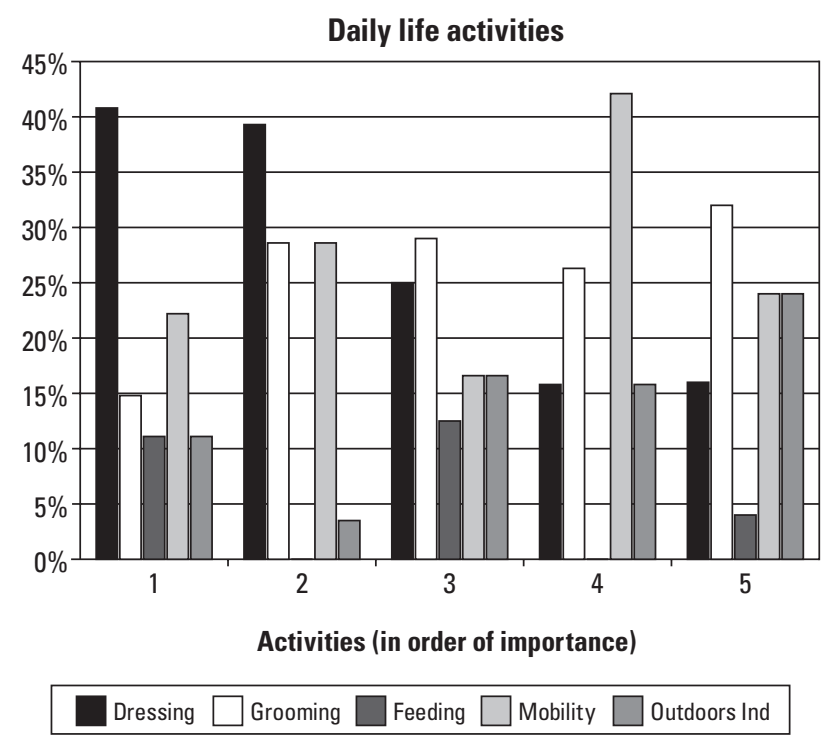

Fig 2. Distribution of tasks related to daily life activities which were most impaired by the spastic hand, in order of importance, according to the patients.

because leaving home with some disability exposes the individual to risks and error probability.

Autonomy loss in DLA was the item that was the most disturbing for patients from that sample, corroborating the study by Cup et al. ${ }^{15}$. 
The performance area rated as productive is found in all levels of need, even with the casuistic being of $100 \%$ of retired individuals, and among the productive activities, performing house chores and taking courses are also included ${ }^{17}$.

Activities related to leisure are not frequently cited by patients. In works on spasticity, that area is not mentioned in terms of autonomy loss, because tasks such as feeding, hygiene, and dressing are essential for human survival, and not because they were preserved. However, that area is extremely important to occupational therapists, because the patient that is characterized as widely disabled due to its deficit in performance is already placed in a position below the level of other individuals in social competition and needs a trigger to react and adhere throughout the required treatment period.

In the validation study for the Canadian Occupational Performance Measure with post-stroke patients by Cup et al. ${ }^{15}, 115$ problems were identified in a sample of 26 individuals, where $45 \%$ in the DLA area, $17 \%$ in the productivity area, and $38 \%$ in the leisure area. In our study, of the 154 problems identified, $80 \%$ are from the DLA area, $15 \%$ in the productivity area, and 5\% in the leisure area which might have been influenced by the social and financial conditions of the population under study, for it is observed that there is a huge difference between the percentage in the DLA and the leisure areas, leading to the hypothesis that there is a difference in the occupational priority among the samples.

In the functional action of the volar dorsal orthosis, hyperexciting the stretching reflex generates an increase in the flexor tonus ${ }^{18}$ of the hand, keeping it with flexed fingers and wrist, thus making the active action of extending and flexing the muscles of the hand difficult. This could be corroborated by the results of the Box and Block Test, where we initially found a low average of 1 block per minute; confirming, thus, the functional loss of the ability of the hand to voluntarily extend and grip, which are essential movements to perform the test. The increase in the average, from 1 to 6 blocks per minute with a significance level of $\mathrm{p}<0.01$, on the disabled side (Table 3 ) confirms a functional improvement. It is hard to correlate the present study to the parameter of the result found in the study by Mendes et al. ${ }^{11}$, with Brazilian individuals that did not have their disability levels changed, aged between 25 and over 65 years, and with an average of 57.3 and 71.4 blocks per minute ${ }^{11}$, since it is methodologically incompatible in terms of the physical dimensions of the evaluation instrument, for the pieces in the current study to have a cylindrical shape, whereas in the study aforementioned, the pieces were square shaped. By adapting the shape of the pieces, we intended to facilitate the patient's grip with the spastic hand, since he/she would not be able to grip any square pieces.
On the normal side (Table 2), the increase in the average from 48 to 59 has also confirmed a functional improvement. Positive functional evolutions of the hand, both on the spastic and normal sides, influenced the improvement in the overall performance.

Zislis ${ }^{19}$ concluded that the orthosis aims at positioning the wrist and the fingers, the prevention of deformities, and pointed out the importance of wearing the orthosis at night, just as proposed in the current study. Preventing deformities is really important after a stroke that develops spasticity, even if it has no influence over the performance of the patient him/herself, only over the caretaker's performance of daily activities, by facilitating the handling of the patient in daily care.

For this work, the choice of the Occupational Therapy treatment through the association of the use of the orthosis with functional training was based on Wolcott ${ }^{20}$, who highlighted efficient results when adding an occupational therapeutic program related to the use of the orthosis in the spastic hand and its use at night, also corroborated by this study.

Teplicky et al. ${ }^{21}$ have referred to the difficulty in corroborating specific results in the use of the orthosis when related to the treatment with Occupational Therapy, which we also found in this study, since the patients were undergoing or had already undergone therapy. We believe it could not be any different for ethical reasons. The influence of therapy on the improvement of performance is undeniable, since the treatment with the use of the orthosis aims at a functional recovery, both through practice and improvement of the occupational performance.

An improvement in performance and personal satisfaction of the patient was observed within this population (Tables 1,2) after using the orthosis. That is a hard conclusion to reach, especially because the Canadian Occupational Performance Measure is not a specifically sensitive evaluation device in terms of orthosis properties (angles, materials, biomechanics), as well as in terms of spasticity aspects, working as a complementary evaluation; however, its methodology provides the patient with a specific identification in terms of disability as well as a more attentive look at the functional changes related to the orthosis, according to the work by McKeee and Ri$\operatorname{vard}^{22}$, who corroborated the hypothesis that the application of that methodology in orthosis interventions help the Occupational Therapist plan the treatment of the patient and build equipment by focusing aspects such as comfort, aesthetics, convenience (usage situations), monitoring the condition, and individual satisfaction.

In order to understand the daily demand for qualification from the individual, it is essential to know the occupational performance areas that are part of that individual's life, that is, the occupational roles referred to by Nelson and Jepson-Thomas ${ }^{16}$, and that he/she performs dai- 
ly. Data related to identification (name, gender, age, civil status, occupation) make it possible to know the occupational roles, that is, the performance demand the individual is subjected to on a daily basis.

The process of building, introducing, and managing the orthosis focused on the patient tends to consider his/ her activities in order to reach the goal and oversee the occupational performance issue. The Occupational Therapist helps the patient know his/her situation, and its impact on his/her occupational performance, as well as helps the patient find a solution due to his/her knowledge of the disease, tissue treatment, biomechanics, orthotic principles, variety of materials and manufacturing tecniques ${ }^{22}$.

For the patients, the influence of the orthosis on performance resides in the comfort of the spastic hand, the improvement in body's positioning, viewing the extended hand, decreasing the sensation of weight in the spastic upper member, decrease in pain and improvement in walking, through an improvement in the control of the upper member, for the scapular waist (upper member) to be really important for the gait due to the fact that it influences posture, balance and step symmetry.

There are evidences as for the advantages the use of the orthosis bring, such as improving positioning, preventing deformities and greater comfort for the patient, due to the principle of decreasing muscle resistance after a certain level of stretching; however, it does not provide lesion repair in the central neurological path, for it has a peripheral action (in extremities).

It was possible to observe that the interest in the patient's personal opinion is of great importance when considering the hierarchy of needs mentioned above, as it becomes the motivational incentive for the patients to comply with the procedure, since the patient is informed at evaluation the purposes of the methodology, which are directly related to the needs of the patient.

The current casuistics leads to the conclusion that the use of wrist and finger orthoses for spasticity after a stroke has proved to be efficient in terms of occupational performance and personal satisfaction.

ACKNOWLEDGMENTS - We thank Dr. Fernando Tondi Guzzo for both his cooperation and English version, and our thanks to the Support Center for Scientific Publications of Santa Casa de São Paulo, Faculty of Medical Sciences for the editorial assistance.

\section{REFERENCES}

1. Guillen G. Acidente vascular cerebral. In: Pedretti LW, Early MB (Eds). Terapia Ocupacional, capacidades práticas para as disfunções físicas. $5^{a}$ ed. São Paulo: Roca, 2004:675-703.

2. Lianza S. Medicina de reabilitação. $4^{a}$ ed. Rio de Janeiro: Guanabara Koogan, 2007.

3. Mathiowetz V, Bolding DJ, Trombly CA. Immediate effects of positioning devices on the normal and spastic hand measured by electromyography. Am J Occup Ther 1983:37:247-254.

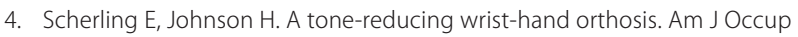
Ther 1989;43:609-611.

5. Lannin NA, Herbert RD. Is hand splinting effective for adults following stroke? A systematic review and methodologic critique of published research. Clin Rehabil 2003;17:807-816.

6. Lannin NA, Cusick A, McCluskey A, Herbert RD. Effects of splinting on wrist contracture after stroke: a randomized controlled trial. Stroke 2007;38:111-116.

7. Pizzi A, Carlucci G, Falsini C, Verdesca S, Grippo A. Application of a volar static splint in poststroke spasticity of the upper limb. Arch of Phys Med Rehabil 2005;86:1855-1859

8. Fess EE, Gettle KS, Philips CA, Janson JR. Splinting for patients with upper extremity spasticity. In: Fess EE, Gettle KS, Philips CA, Janson JR (Eds). Hand and upper extremity splinting, principles and methods. $3^{\mathrm{a}} \mathrm{ed}$. St. Louis, Missouri: Elsevier Mosby, 2005:517-536

9. Mathiowetz V, Volland G, Kashman N, Weber K. Adult norms for the Box and Block Test of manual dexterity. Am J Occup Ther 1985;39:386-391.

10. Desrosiers J, Bravo G, Hebert R, Dutil E, Mercier L. Validation of the Box and Block Test as a measure of dexterity of elderly people: reliability, validity, and norms studies. Arch Phys Med Rehabil 1994;75:751-755.

11. Mendes MF, Tilbery CP, Balsimelli S, Moreira MA, Cruz AMB. Teste de destreza manual da caixa e blocos em indivíduos normais e em pacientes com esclerose múltipla. Arq Neuropsiquiatr 2001;59:889-894.

12. Hinderer SR, Dixon K. Physiologic and clinical monitoring of spastic hypertonia. Phys Med Rehabil Clin N Am 2001;12:733-746.

13. Pfister AA, Roberts AG, Taylor HM, Noel-Spaudling S, Damian MM, Charles PD. Spasticity in adults living in a developmental center. Arch Phys Med Rehabil 2003:84:1808-1812.

14. Satkunam LE. Rehabilitation medicine: 3. Management of adult spasticity. Can Med Assoc J 2003;169:1173-1179.

15. Cup EH, Scholte op Reimer WJ. Thijssen MC, Kuyk-Minis MA. Reliability and validity of the Canadian Occupational Performance Measure in stroke patients. Clin Rehabil 2003;17:402-409.

16. Nelson DL, Jepson-Thomas J. Occupational form, occupational performance, and a conceptual framework for therapeutic occupational. In: Kramer P, Hinojosa J, Royeen CB (Eds). Perspectives in Human Occupation-Participation in Life. Baltimore: Lippincott Williams e Wilkins. 2003:87-155.

17. Youngstrom MJ. Occupational Therapy Practice Framework: domain an process. The Am J Occup Ther 2002;56:609-639.

18. Kandel ER, Schwartz JH, Jessell TM. A organização funcional da percepção e do movimento. In: Princípios da neurociência In: Kandel ER, Schwartz JH, Jessell TM (Eds). São Paulo: Manole, 2003:337-348.

19. Zislis JM. Splinting of hand in a spastic hemiplegic patient. Arch Phys Med Rehabil 1964;45:41-43.

20. Wolcott LE. Orthotic management of the spastic hand. South Med J 1966;59: 971-974.

21. Teplicky R, Law M, Russell D. The effectiveness of casts, orthoses, and splints for children with neurological disorders. Inf Young Children 2002;15:42-50.

22. McKee P, Rivard A. Orthoses as enablers of occupation: client-centred splinting for better outcomes. Can J Occup Ther 2004;71:306-314. 